of water. Rather is the kinetic energy of the drop dissipated in shock and splash at the surface, and thus the sphere of influence of the drop is not as great as suggested by Reynolds.

E. W. S. Ashton

J. K. O'SULLIVAN

Engineering Department,

University, Manchester.

Feb. 18.

'Reynolds, O., "Papers Mechanical and Physical Subjects", 86 (Camb. Univ. Press).

\section{Hydroxylysine and Lysine in Wool}

IN order to estimate the lysine content of wool, using partition chromatography on silica gel $^{1}$, a sample of ethanol-and ether-extracted wool (Lincoln Hogg, tips removed) was hydrolysed at the boil with $5 \cdot 7 \mathrm{~N}$ hydrochloric acid for twenty-four hours. An aliquot was then treated with 1-fluoro-2:4-dinitrobenzene and an unsuccessful attempt made to separate the di-2:4 dinitrophenyllysine from the other amino-acid derivatives by means of suitable solvents ${ }^{2}$, owing to considerable overlapping of the various 2:4-dinitrophenyl amino-acids. However, making use of Porter and Sanger's copper complex technique for the preparation of $-\varepsilon \mathrm{N}-2$ : 4-dinitrophenyllysine ${ }^{3}$, a relatively simple method for the quantitative estimation of lysine was developed, using a hydrolysate solution containing the equivalent of 5-10 mgm. of the original wool.

The treated material was taken up in a 30 per cent butanol-chloroform mixture and run on a silica gel column with water as the stationary phase ${ }^{2}$. Two bands were formed, one strong, with $R_{F}=0 \cdot 18$, and the other weak, with $R_{F}=0 \cdot 047$. The strong band was run out, the solvent evaporated off in vacuo, dissolved in $N$ hydrochloric acid and estimated colori. metrically with a photo-electric absorptiometer. This substance had $R_{F}=0 \cdot 27$ on a 66 per cent methyl ethyl ketone-ether column, and was found to be identical with an authentic sample of - $\varepsilon \mathrm{N}-2: 4$ dinitrophenyllysine. Lysine content of wool was $3 \cdot 38 \pm 0.03$ per cent ( 3.86 per cent T.P.N.).

When a sample of gelatin hydrolysate known to contain hydroxylysine 5,6 was treated as above, both bands were found; but the slower band was relatively stronger than in the previous case. As in the case of wool the slower band had $R_{F}=0.12$ on a 66 per cent methyl ethyl ketone-ether column, and was found to be identical with the slower band obtained from a treated sample of hydroxylysine known to contain lysine, from Mr. J. G. Heathcote, Cereals Research Station, St. Albans. Hydroxylysine content of wool was $0 \cdot 18$ per cent. No great accuracy is claimed for this value, as sufficient pure hydroxylysine was not available for an accurate standardization curve. However, this value corresponds to a minimum molecular weight of 91,000. Van Slyke et al. ${ }^{7}$ claimed to have found hydroxylysine in wool ; but Macpherson ${ }^{5}$ was unable to find any.

A mixture of amino-acids containing a known amount of lysine has not yet been analysed by this method.

When wool was treated with 1-fluoro-2:4-dinitrobenzene, and hydrolysed in hydrochloric acid, all the lysine was converted to - $\varepsilon \mathrm{N}$-dinitrophenyllysine, and no $-\varepsilon \mathrm{N}$-dinitrophenyl-hydroxylysine was found, although the latter was stable to acid hydrolysis.
Thus, the $-\varepsilon \mathrm{NH}_{2}$ groups of hydroxylysine may not be free, but linked to form $-\varepsilon \mathrm{N}$ peptides or other groups which liberate amino groups on hydrolysis.

W. R. MIDDLEBROOK

(International Wool Secretariat Research Fellow)

Textile Chemistry Laboratory, Department of Textile Industries, University, Leeds 2.

${ }^{1}$ Gordon, A. H., Martin, A. J. P., and Synge, R. L. M., Biochem. J., 37, 79 (1943).

2 Sanger, F., Biochem. J., 39, 507 (1945).

${ }^{3}$ Porter, R. R., and Sanger, F., Biochem. J., 42, 287 (1948)

+ Van Slyke, D. D., Hiller, A., Dillon, R., and MacFadyen, D. A., Proc. Soc. Exp. Biol. and Med., 38, 548 (1938).

${ }^{5}$ Macpherson, H. T., Biochem. J., 40, 470 (1946).

${ }^{6}$ Heathcote, J. G., Biochem. J., 42, 305 (1948).

" Van Slyke, D. D., Hiller, A., and MacFadyen, D. A., J. Biol. Chem., 141,681 (1941).

\section{Evaporation of Water from Woodlice}

THE presence of a waxy layer at or near the outer surface of the epicuticle of insects is well known, and its function in limiting the permeability of the insect integument to water has been fully demonstrated by Wigglesworth ${ }^{1}$, Beament ${ }^{2}$ and others. Yonge ${ }^{3}$ has demonstrated the effect of the epicuticle of certain Crustacea in determining permeability to many substances, and Dennel ${ }^{4}$ has shown that phenolic tanning, as in insects, occurs in the hardening of the crustacean epicuticle. Dennel further suggests that tanning of the crustacean cuticle may, by facilitating impregnation with lipophilic substances, serve to limit permeability as well as to prevent abrasion.

The permeability of the cuticle of terrestrial crustacea to water is clearly of interest in this connexion, and it has been investigated in a number of terrestrial isopods. The animals were kept, ten at a time but separated from each other, in slowly moving dry air at various temperatures for periods of fifteen minutes, and the amount of water lost by each individual was found by weighing immediately before and after exposure. Living animals were used, as preliminary experiments showed that there was no difference in the rate of evaporation from living and recently killed specimens. Many were, of course, dead after exposure to the higher temperatures.

The accompanying figure shows the curves obtained, for some of the species used, when rate of loss is plotted against saturation deficit on a linear scale. The curves are approximately linear, and they show that evaporation from woodlice conforms to Dalton's law, at least in dry air between $10^{\circ}$ and $60^{\circ} \mathrm{C}$. The curve for Glomeris, a millipede which occupies the same ecological niche as some woodlice, also appears in the figure, and it, too, is approximately linear up to $50^{\circ} \mathrm{C}$., above which the increase in rate of evaporation falls i $\mathrm{ff}$.

The curve for an insect (Pieris larvæ), derived from Wigglesworth's data, is shown for comparison. Insects, as Ramsay ${ }^{5}$ and Wigglesworth have shown, lose very little water below a critical temperature (which varies greatly from one kind of insect to another); but the rate of loss rises steeply with temperature above this point, and the critical temperature corresponds with a change in phase of the waxy layer of the epicuticle. There is no indication of such a critical temperature in woodlice, however, and this suggests that they lack a waxy layer in the epicuticle. 